\title{
Enfermedad veno-oclusiva hepática, colitis ulcerosa idiopática y trombosis portal: Comunicación de un caso clínico
}

\author{
José $M$ Valera $M^{\mathbf{1}}$, Chun Nei Lu $C^{\mathbf{1}}$, Gladys Smok $S^{\mathbf{2}}$, \\ Manuel Fernández $\mathrm{A}^{3}$, Carlos Regonesi $\mathrm{M}^{4}$, Javier Brahm $\mathrm{B}^{1,5}$. \\ Hepatic veno-occlusive disease, \\ idiopathic ulcerative colitis and \\ portal thrombosis. Report of one case
}

We report a previously healthy 29 years old man, presenting with a sudden episode of abdominal pain, mild jaundice, hepatomegaly and ascites. Magnetic resonance imaging study and liver biopsy were compatible with veno-occlusive disease. Incidentally, an ulcerative colitis and portal vein thrombosis were diagnosed. Anticoagulant treatment was started, with good clinical and radiological response. Veno-occlusive disease of the liver must be suspected in cases of liver failure and ascites associated to procoagulant conditions (Rev Méd Chile 2004; 132: 1091-5).

(Key Words: Colitis, ulcerative; Hepatic veno-occlusive disease; Portal vein thrombosis)

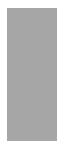

Recibido el 12 de mayo, 2004. Aceptado el 12 de julio, 2004.

${ }^{1}$ Sección de Gastroenterología y ${ }^{2}$ Departamento de Anatomía Patológica, Hospital Clínico Universidad de Chile. Departamentos de ${ }^{3}$ Radiología, ${ }^{4}$ Hemato-oncología y ${ }^{5}$ Gastroenterología, Clínica Las Condes, Santiago, Chile.

L a enfermedad veno-oclusiva hepática (EVOH) se caracteriza por una obstrucción de las venas hepáticas centrales y pequeñas, sin afectación de las venas suprahepáticas propiamente tales. Se le conoce también como la forma radicular del Budd-Chiari o síndrome de Stuart-Bras ${ }^{1}$. Es una patología infrecuente asociada con varias condiciones, entre las que destacan el trasplante de médula ósea ${ }^{2}$ y el uso de algunas drogas inmuno-

Correspondencia a: Dr. Javier Brahm B. Sección Gastroenterología, Hospital Clínico Universidad de Chile. Avda. Santos Dumont 999, Santiago, Chile. Fono: 6788350. Fax: 6788349. E mail: jbrahm@redclinica.cl moduladoras y antineoplásicas ${ }^{3,4}$. Puede presentarse en cualquier edad y sexo.

Las manifestaciones clínicas pueden ser agudas, subagudas o crónicas, con desarrollo de ictericia, hepatomegalia y ascitis, lo que incluso puede dificultar el estudio histológico del hígado con biopsia percutánea. Dado que la efectividad de su manejo se asocia con un diagnóstico precoz, requiere un alto índice de sospecha.

Se presenta el caso de un paciente que desarrolló un cuadro clínico compatible con $\mathrm{EVOH}$, que al estudiarse aparecieron patologías concomitantes y que se trató precozmente con favorable evolución posterior. 


\section{CASO CLÍNICO}

Hombre de 29 años, fumador de 10 cigarrillos/día, sin otros antecedentes mórbidos. En noviembre de 2002 fue derivado desde provincia por un cuadro de 3 días de evolución caracterizado por fiebre, dolor abdominal de predominio en hipocondrio derecho y hepatomegalia. Al examen físico destacaba ascitis evidente y dolor a la palpación de flanco derecho. El estudio de laboratorio mostró bilimubina total de 1,2 gr/ dl, transaminasa glutámica oxaloacética el doble de lo normal y transaminasa glutámica pirúvica aumentada en cinco veces su valor normal, fosfatasas alcalinas normales, $\gamma$-glutamil transferasa elevada una y media vez lo normal, tiempo de protrombina $80 \%$, hematocrito $40 \%$ y plaquetas $145.000 \mathrm{x} \mathrm{mm}^{3}$. La punción de líquido ascítico mostró transudado mononuclear y en la endoscopia digestiva alta (EDA) no tenía hallazgos significativos.

En el estudio de imágenes, la ecografía doppler y la tomografía axial computada (TAC) de abdomen mostraron ascitis moderada, hepato-esplenomegalia y sistema venoso suprahepático y portal permeable, con flujo hepatopeto. Se complementó con resonancia magnética (RM) de hígado y eje vascular, en que se observaron venas suprahepáticas (VSH) de un calibre muy fino, pero sin trombosis, vena cava inferior (VCI) permeable, con reducción importante del calibre en su porción intrahepática e hígado heterogéneo con

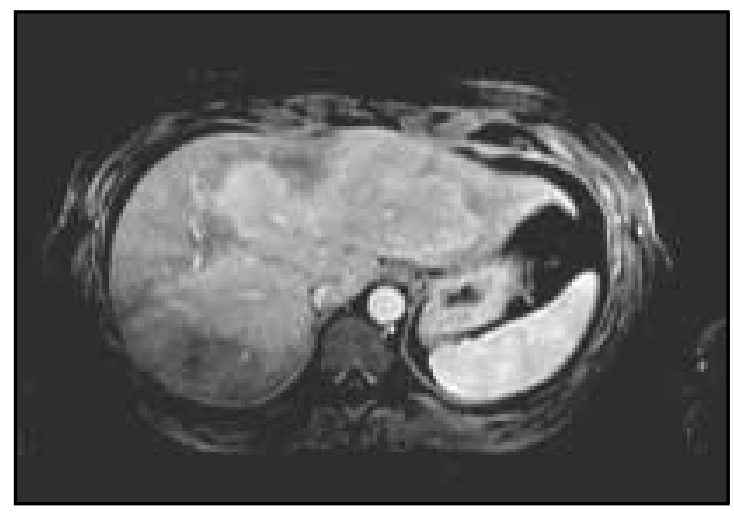

FIGURA 1. Imagen de RM con contraste paramagnético (gadolinio) en fase portal precoz que muestra un patrón de aumento de señal moteado en la región central del hígado con edema periportal, la VCI comprimida y las VSH de calibre muy fino. edema periportal y porta permeable. Se informó sugerente de EVOH (Figura 1).

Se realizó biopsia hepática percutánea que describió colestasia canalicular leve, congestión y necrosis centrolobulillar, trombosis de vénula terminal con fibrosis perivenular y perisinusoidal, compatible con EVOH (Figura 2).

Dado que el paciente refería en la historia una diarrea crónica intermitente, se practicó una colonoscopia completa que mostró una colitis ulcerosa izquierda activa, cuya biopsia fue compatible con colitis ulcerosa idiopática (CUI) leve a moderada.

El estudio inmunológico fue normal, con anticuerpos antiantígenos extractables del núcleo, antinucleares, antimúsculo liso, anticentrómero y anticardiolipinas negativos. En el estudio de trombofilia destacaba la proteína $\mathrm{C}$ en límite bajo (68\%, VN: 65-160\%), con antitrombina III, proteína S y resistencia a la proteína $\mathrm{C}$ activada normales. PCR del factor $\mathrm{V}$ no detectó mutación, con homocisteína y folato (sérico y eritrocítico) normales.

Fue dado de alta con diagnósticos de EVOH, hipertensión portal secundaria y CUI, indicándosele mantener tratamiento con prednisona, mesalazina y espironolactona.

Reingresó una semana después por una dermatitis que se atribuyó a la mesalazina y un dudoso sangrado digestivo. El laboratorio fue similar al previo, pero el doppler y la RM mostraron trombosis parcial reciente de la porta derecha (VP) y mesentérica superior (VMS), con VSH y

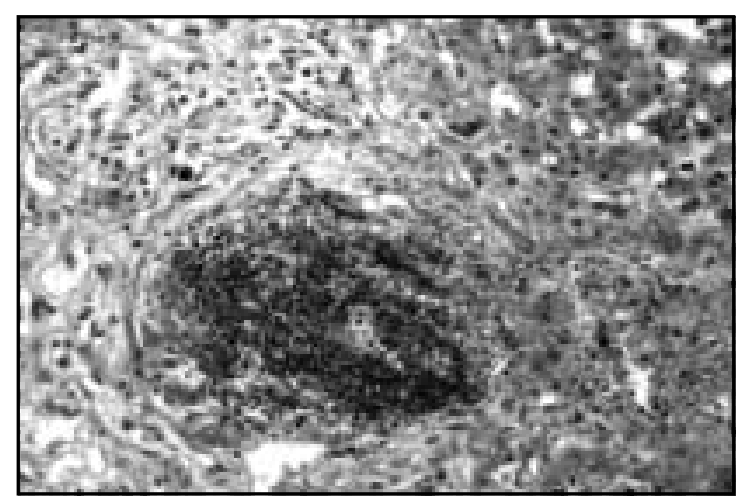

FIGURA 2. Vénula hepática terminal con depósito de colágeno y trombosis reciente (tinción tricrómica Van Gieson 40x). 
VCI permeables y ascitis mínima. La EDA y colonoscopia fueron negativos para hemorragia digestiva. Se inició anticoagulación con heparina intravenosa y luego oral con acenocumarol. Fue dado de alta en buenas condiciones con los diagnósticos ya descritos y en tratamiento anticoagulante.

Evolucionó en forma satisfactoria, activo y trabajando, con diarrea y dolor abdominal leve ocasional. Los exámenes de laboratorio de control fueron normales y la RM cinco meses más tarde mostró hígado de volumen normal con parénquima más homogéneo, VSH y segmento de VCI intrahepática permeables y con buena señal, pero aún de pequeño calibre. Destacaba además que la VP y VMS se habían recanalizado, sin trombos en su lumen y con flujo hepatopetal (Figura 3); no había ascitis y el bazo era de tamaño normal.

\section{DisCUSIÓN}

La EVOH se ha descrito asociada en su patogenia a varias condiciones de naturaleza tóxica o un daño mecánico, que conduce a la obstrucción venular descrita. Se documentó inicialmente en Jamaica en $1951^{1}$ por intoxicación crónica con alcaloides de pirrolizidina, que se encuentra en diversas plantas usadas como té medicinal o en cereales contaminados ${ }^{5}$. Entre 1974 y 1978 se produjo un brote epidémico en Afganistán e India, por el consumo local de cereales contaminados con este alcaloide. Otras causas importantes incluyen trasplante de médula ósea ${ }^{2}$, uso de agentes citostáticos, inmunomoduladores como azatioprina y ciclofosfamida 3,4 , condiciones protrombóticas como síndrome mieloproliferativo (ej: policitemia vera), lupus sistémico ${ }^{6}$, uso de anticonceptivos orales ${ }^{7}$ y también se ha descrito en hepatitis alcohólica ${ }^{8}$. Es importante considerar la $\mathrm{EVOH}$ en las primeras semanas que siguen al trasplante de médula ósea, lo que sería una reacción a la inducción del tratamiento citotóxico, alcanzando una incidencia de $25 \%$ en trasplantes alogénicos y una mortalidad cercana a $30 \%{ }^{9}$.

En nuestro paciente destaca que no presentaba, aparentemente, los factores de riesgo descritos para EVOH. Sin embargo, es importante considerar el nivel cercano al límite inferior que mostró el estudio de la proteína $\mathrm{C}$, lo que sumado a su CUI,

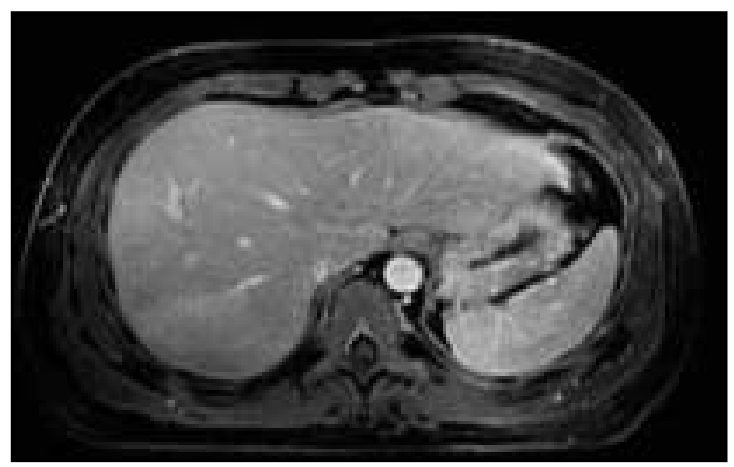

FIGURA 3. Imagen con contraste y fase similar a la RM anterior en que se observa parénquima homogéneo y sin edema.

que puede asociar un estado procoagulante como manifestación extraintestinal ${ }^{10}$, desarrolló la EVOH y contemporáneamente una trombosis portal y mesentérica, lo que sugiere un mecanismo común en su patogenia. Al tener imágenes muy recientes, con eje vascular permeable al momento de su presentación inicial, la trombosis de novo pesquisada precozmente tuvo muy buena resolución, recanalizándose con el tratamiento anticoagulante.

En relación al estudio histológico, éste es muy útil, pero puede dar falsos negativos, porque la muestra suele ser muy pequeña para representar el compromiso heterogéneo de la enfermedad ${ }^{11}$. Recientes estudios sugieren que la injuria tóxica afecta inicialmente a las células endoteliales sinusoidales, seguido por una serie de procesos biológicos que comprometen a los hepatocitos centrolobulillares con fibrosis y obstrucción al flujo hepático. Hay proliferación de células estrelladas perisinusoidales y de fibroblastos subendoteliales en la vena hepática terminal, con posterior depósito de colágeno y obliteración progresiva, cuya persistencia lleva a fibrosis perivenular irradiada al parénquima, siendo poco frecuente la cirrosis, pero puede haber necrosis o atrofia del parénquima ${ }^{12}$. Se produce, secundariamente, una hipertensión portal posthepática.

Es importante descartar otras condiciones clínicamente parecidas, como las alteraciones de las pruebas hepáticas en las primeras semanas de la enfermedad de injerto versus huésped, causas congestivas, como Budd-Chiari e insuficiencia cardíaca, reacciones a drogas, efectos tóxicos de la hiperalimentación, infecciones como hepatitis virales, hongos o sepsis ${ }^{9}$. 
En nuestro caso, se presentó el paciente con dolor abdominal, ascitis y hepatomegalia, con alteración leve de pruebas hepáticas y buena síntesis hepatocelular, lo cual sugiere una obstrucción al flujo venoso posthepático. Los estudios de imágenes han mostrado buena sensibilidad y especificidad, destacando el eco doppler ${ }^{13}$ y la RM que sugirió el diagnóstico al describir una reducción notoria del calibre de las venas intrahepáticas ${ }^{14,15}$.

Se describe que hasta $10 \%$ de los casos de EVOH pueden ser asintomáticos por un largo período, como también pueden progresar rápidamente a la insuficiencia hepática 0 , en cursos crónicos, a la cirrosis con hipertensión portal postsinusoidal. En este sentido, sería de utilidad para el diagnóstico precoz y monitorización, la medición del propéptido para procolágeno tipo III ${ }^{16}$, como también serían de valor predictivo el factor VIII, proteína $\mathrm{C}$ y el ácido hialurónico ${ }^{11}$, no disponibles en nuestro caso.

En cuanto al tratamiento, debe eliminarse la causa, si es posible, siendo un manejo más bien sintomático de la hipertensión portal con diuréticos, eventual paracéntesis, beta bloqueadores y el TIPS en casos de difícil manejo ${ }^{17}$. También se ha considerado como indicación de trasplante hepáti$\mathrm{CO}^{2}$. El tratamiento de la EVOH propiamente tal es complejo y están en estudio marcadores que

\section{REFERENCIAS}

1. Bras G, Jeluffe DB, Stuart KL. Veno-occlusive disease of the liver with non-portal type of cirrhosis occurring in Jamaica. Arch Pathol 1954; 57: 285-300.

2. Norris S, Crosbie O, McEntee G, Traynor O, Molan $\mathrm{N}$, McCann S et al. Orthotopic liver transplantation for veno-occlusive disease complicating autologous bone marrow transplantation. Transplantation 1997; 63: 1521-4.

3. Hola K, Brahm J, Alvo M, Cotera A, Passalacqua W, Sмок G. Hepatic veno-occlusive disease associated to the use of azathioprine in a renal transplant recipient. Rev Méd Chil 1996; 124: 1489-91.

4. Modzelewski JR, Daeschner C, Joshi VV, Muшck FG, IsHAK KG. Veno-occlusive disease of the liver induced by low-dose cyclophosphamide. Modern Pathol 1994; 7: 967-72. ayuden a un diagnóstico precoz, junto a un manejo de mayor eficacia antitrombótica con el uso de tPA, antitrombina III o defibrotide ${ }^{18}$. Se ha ensayado el manejo profiláctico con ácido ursodeoxicólico, heparina continua y de bajo peso molecular en los pacientes que requieren trasplante alogénico de médula ósea ${ }^{19,20}$. En nuestro paciente, el tratamiento anticoagulante estándar fue motivado precozmente por la trombosis portomesentérica e indujo una evolución favorable del compromiso postsinusoidal, probablemente en relación a la estasia con microtrombosis que se describió histológicamente a ese nivel, mostrando el hígado con volumen y flujo más normal, sin hipertensión portal al 5o mes.

En suma, la EVOH es un diagnóstico infrecuente que debe sospecharse precozmente en casos de insuficiencia hepatocelular e hipertensión portal en las situaciones expuestas, como ocurrió en nuestro caso que presentaba factores procoagulantes. Es fundamental el estudio con imágenes como doppler y RM e idealmente, una biopsia hepática para iniciar precozmente su manejo. En nuestro caso se acompañó de trombosis porto-mesentérica que requirió anticoagulación, evolucionando favorablemente con mejoría clínica y en las imágenes, lo que refuerza el estudio y uso de terapias antitrombóticas eficaces.

5. Ortiz Cansado A, Crespo Valades E, Morales Blanco P, Sáenz de Santamaría J, González Campilejo JM, Ruzz Téwez T. Enfermedad veno-occlusiva hepática por ingestión de infusiones de senecio vulgaris. Gastroenterol Hepatol 1995; 18: 413-6.

6. Pappas SC, Malone DG, Rabin L, Hoofnagel YH, JoNES EA. Hepatic veno-occlusive disease in a patient with systemic lupus erythematosus. Arthr Rheumatol 1984; 27: 104-8.

7. ALPERT LI. Veno-occlusive disease of the liver associated with oral contraceptives: case report and review of the literature. Hum Path 1976; 7: 709-18.

8. Kishi M, Maeyama S, Iwaba A, Ogata S, Koike J, Uснікоsнi T. Hepatic veno-occlusive lesions and other histopathological changes of the liver in severe alcoholic hepatitis, a comparative clinicohistopathological study of autopsy cases. Alcohol Clin Exp Res 2000; 24 (4 Suppl): 74S-80S. 
9. SHERLOCK S, DOOLEY J. Drugs and the Liver. In: Diseases of the Liver and Biliary System. 11th ed. Blackwell Science, 2002; 349.

10. Valera JM, Morales A. Manifestaciones extraintestinales de la Enfermedad de Crohn (e inflamatoria intestinal). Rev Hospital Clínico U de Chile 2001; 12: 185-91.

11. Yoshimoto K, Ono N, Okamura T, Sata M. Recent progress in the diagnosis and therapy for venoocclusive disease of the liver. Leuk Lymphoma 2003; 44: 229-334.

12. Deleve LD, Shulman HM, McDonald GB. Toxic injury to hepatic sinusoids: sinusoidal obstruction syndrome (veno-occlusive disease). Semin Liver Dis 2002; 22: 27-42.

13. Teefey SA, Brink JA, Borson RA, Middieton WD. Diagnosis of veno-occlusive disease of the liver after bone marrow transplantation: value of duplex sonography. Amer J Roentgenol 1995; 164: 1397-401.

14. Mortele KJ, Van Vluerberghe H. Hepatic venoocclusive disease: MRI findings. Abdom Imaging 2002; 27: 523-6.
15. Jansen TLTA, De Vries RA, Kesselring, FOHW, Meijer JWR. Magnetic resonance imaging in the staging of hepatic veno-occlusive disease. Eur J Gastroenterol Hepatol 1994; 6: 453-6.

16. Eltumi M, Trivedi $P$, Hobbs JR, Portmann B, CheeseMAN P, DownIE C ET AL. Monitoring of venoocclusive disease after bone marrow transplantation by serum amino-propeptide of type III procollagen. Lancet 1993; 342: 518-21.

17. RaJvanshi P, McDonadD GB. Expanding the use of transjugular intrahepatic portosystemic shunts for veno-occlusive disease. Liver Transpl 2001; 7: 154-7.

18. WILNER IR. Veno-occlusive Disease. Curr Treat Options Gastroenterol 2002; 5: 465-9.

19. BEARMAN SI. Avoiding hepatic veno-occlusive disease: what do we know and where are we going? Bone Marrow Transplant 2001; 27: 1113-20.

20. Forrest DL, Thompson K, Dorcas VG, Couban SH, PIERCE R. Low molecular weight heparin for the prevention of hepatic veno-occlusive disease (VOD) after hematopoietic stem cell transplantation: a prospective phase II study. Bone Marrow Transplant 2003; 31: 1143-9. 